\title{
PARAPLEGIA AND CARDIAC ARREST: CASE REPORTS
}

\author{
G. R. GODE, D.A., F.F.A.R.C.S.(ENG.) ${ }^{*}$
}

Clinical LITERature discusses a variety of complications which may affect the paraplegic patient. The attending physician must take special care of thesc patients to prevent and, if necessary, to treat these complications. A paraplegic individual is not uncommonly a candidate for a surgical procedure. It has not been sufficiently stressed in the literature that such a patient readily suffers from shock due to autonomic imbalance with loss of sympathetic tone. The hazard of profound hypotension, resulting in cardiac arrest when the anaesthetized paraplegic patient's position was altered, is emphasized by two episodes observed in this hospital. Both patients could be resuscitated and one of them was again anaesthetized and operated upon 16 days after the episode of cardiac arrest.

\section{Case Reports}

\section{Case 1}

A female patient, 34 years old, was admitted with complaints of low backache (three years) and paraplegia (one year). A diagnosis of Koch's lesion at $\mathrm{x}-7-8$ with kyphosis was made after clinical and radiological investigations. Blood pressure was $150 / 100 \mathrm{~mm} \mathrm{Hg}$, and clinical and laboratory investigations were in a normal range. She was scheduled for spinal decompression on January 23, 1967.

The patient was premedicated with atrophine $0.6 \mathrm{mg}$, meperidine $50 \mathrm{mg}$, and promethazine $25 \mathrm{mg}$ given intramuscularly, 45 minutes before induction of anaesthesia. Anaesthesia was induced with $350 \mathrm{mg}$ thiopentone sodium injected intravenously, followed by $75 \mathrm{mg}$ suxamethonium, and a cuffed endotracheal tube was inserted. When the patient started to breathe spontaneously, nitrous oxide, oxygen, and ether were introduced into the Magill's circuit. She was then turned into the prone position on the table, and while the anaesthetist found that the pulse was of small volume, it disappeared under his fingers. The colour of the face changed to ashen grey and heart sounds could not be heard on auscultation. The patient was quickly turned to the supine position, the head was lowered, and the lungs were ventilated with 100 per cent oxygen. The heart sounds being still inaudible, external cardiac compression was started about $1 / 2$ minutes after the disappearance of the pulse.

Spontaneous function of heart and respiration returned 11 minutes after starting resuscitative measures. During this period intracardiac adrenaline $(6 \mathrm{ml}, 1: 10$,000 ), intravenous calcium chloride ( $6 \mathrm{ml}, 10$ per cent) and intravenous sodium bicarbonate ( $50 \mathrm{ml}, 7.5$ per cent) were administered in divided doses and a noradrenaline drip was administered intravenously. After transfer to the recovery

'Department of Anaesthesiology, All India Institute of Medical Sciences, New Delhi.

452

Canad. Anaesth. Soc. J., vol. 17, no. 5, September 1970 
room, mannitol ( $500 \mathrm{ml}, 20$ per cent) was given intravenously in a drip and the rectal temperature of the patient was maintained at $34^{\circ}-35^{\circ} \mathrm{C}$ for the next 24 hours by using a cooling blanket. The patient made a complete recovery during the next three days, at the end of which the relatives removed her from hospital against medical advice, refusing any future operative procedure.

\section{Case 2}

A female patient, 26 years old, was admitted with a complaint of inability to walk and of multiple swellings in different parts of the body. The condition, of one year's duration, was diagnosed as multiple neuro-fibromata and the myelogram showed the upper limit of block at T-5. Laminectomy and excision of the neuro-fibromatous growth was planned on February 27, 1968, to remove the compression. Clinical and laboratory findings were within normal range.

The patient was premedicated with atrophine $0.6 \mathrm{mg}$, meperidine $50 \mathrm{mg}$, and promethazine $25 \mathrm{mg}$ injected by the intramuscular route about an hour before the induction of anaesthesia with thiopentone sodium $300 \mathrm{mg}$ and suxamethonium 75 mg administered by the intravenous route. After a cuffed endotracheal tube was introduced, the patient was allowed to breathe spontaneously from a Magill's circuit. The anaesthetic mixture was nitrous oxide $5 \mathrm{~L} / \mathrm{min}$, oxygen $3 \mathrm{~L} / \mathrm{min}$, and ether. The blood pressure recorded after stabilization of the anaesthetic plane was the same as before induction (120/80 mm Hg). The patient was then lifted from the trolley and placed in the prone position on the operation table. As the table was being adjusted to a suitable position, the anaesthetist noticed that the breathing movements were absent and that pulses at the wrist and neck were not palpable, heart sounds not audible, and pupils widely dilated. The patient was quickly turned again to the supine position. Ventilation with 100 per cent oxygen and external cardiac compression was instituted and continued for five minutes. During this period a noradrenaline drip was started, $25 \mathrm{ml}$ of 7.5 per cent sodium bicarbonate solution was injected intravenously and the chest was opened. The heart was found to be fibrillating. Two shocks ( 100 volts, 0.5 seconds with AC defibrillator) resulted in the establishment of a spontaneous heartbeat. The chest was then closed and the patient was cooled and maintained at $35^{\circ} \mathrm{C}$ for 24 hours. Because the patient made a satisfactory clinical recovery and ECG and other investigations were found to be within normal range, and because loss of motor power in the lower limbs was rapidly progressing, she was accepted for anaesthesia and surgery 16 days after the episode of cardiac arrest.

After premedication the lower limbs of the patient were firmly bandaged with elastic bandage. The operating table was kept in the Tredelenburg (about $20^{\circ}$ ) position before induction of anaesthesia. Continuous ECG monitoring was carried out throughout the anaesthetic procedure. After preoxygenation for 10 minutes, anaesthesia was induced with a slow injection of thiopentone sodium ( $200 \mathrm{mg}$ ). This was followed by suxamethonium $75 \mathrm{mg}$ intravenously, and a cuffed endotracheal tube was inserted. After the patient was stabilized with $\mathrm{N}_{2} \mathrm{O}-\mathrm{O}_{2}$-ether anaesthesia in a Magill's circuit, controlled ventilation was instituted with a toand-fro circuit with the aid of $15 \mathrm{mg}$ d-tubocurarine as an initial dose. A small incremental dose ( $4 \mathrm{mg}$ ) was repeated during the procedure whenever it was 
found necessary. Anaesthesia was maintained with nitrous oxide and oxygen (60 per cent and 40 per cent $\mathrm{v} / \mathrm{v}$ ) in closed circuit with a carbon dioxide absorption system.

Blood pressure was checked every five minutes. Position was changed to prone in stages, first to the lateral and after five minutes to prone position with proper supports Laminectomy of $\mathrm{T}-5,6,7$, and 8 was carried out and the tumour mass was removed. Blood $(600 \mathrm{ml})$ was transfused as it was lost. All precautions were taken to prevent hypotension. During surgery the blood pressure was labile and showed a marked tendency to fall rapidly. This demanded careful and frequent adjustments of anaesthetia and the rate of blood transfusion. At the end of operation the effect of curare was reversed by a neostigmine-atropine mixture. The patient made a good recovery.

\section{Discussion}

When an individual assumes the erect position, the blood tends to gravitate to the organs below the level of the heart. However, due to sympathetic vasoconstrictor impulses the gravitational pooling of blood is prevented. This and other regulatory mechanisms do not work adequately in paraplegic patients as lesions of the spinal cord interfere with the autonomic vascular control. Individuals having lesions at higher levels of the spinal cord are likely to suffer more severely than those with lesions in lower regions.

Polock et al. ${ }^{1}$ reported orthostatic hypotension in ten cases with cervical cord lesions. A basal systolic blood pressure ranging from 80 to $150 \mathrm{~mm} \mathrm{Hg}$ fell precipitously to such a degree that it could not be recorded either by auscultation or by palpation when these patients were tilted from horizontal to a vertical position. It is not surprising that in eight of the ten cases unconsciousness resulted. Williams et al. ${ }^{2}$ have reported that of four paraplegic patients submitted to surgical procedures, three showed severe hypotension that could not be accounted for by the blood loss, the anaesthetic procedure, or the suprapubic cystostomy. The blood pressure dropped to $60 / 35 \mathrm{~mm} \mathrm{Hg}$ from 130/76 when the patient was anaesthetized and subjected to change of position before the operation started. Hunter ${ }^{3}$ has warned against the severe cardiovascular collapse in paraplegic patients with the usual dose of thiopentone; this susceptibility to thiopentone again can be explained on the basis of failure of compensatory vasoconstriction in these patients.

Most of the agents used for inducing and maintaining anaesthesia are vasodilators due to their effect on central as well as peripheral mechanisms, and some of them have an effect on heart, reducing cardiac output. Thus a certain degree of fall in blood pressure is usually observed at the time of induction of anaesthesia. The danger is exaggerated when a paraplegic patient with impaired mechanism of compensatory vasoconstriction is anaesthetized and then immediately subjected to a change of position. The two cases reported here present two peculiarities. In both, the hypotension was so severe that it resulted in cardiac arrest; and, in both, the hypotension occurred immediately after change of posture of the anaesthetized patient. 
Case 2 demonstrates that the management of anaesthetic and surgical procedures in paraplegic patients should be carried out with special precautions and a cautious attitude against hypotension. When such precautions were taken the procedure was without mishap at the second anaesthetic procedure. Hypertension, instead of hypotension, has been described in some cases of transection of the spinal cord, ${ }^{4}$ but it is noteworthy that these cases are mainly transection of the cord which is traumatic in origin.

\section{Incidence of hypotension}

The serious complication of cardiac arrest in our cases prompted us to study the incidence of hypotension in paraplegic patients. Williams et al. ${ }^{2}$ have stated the incidence of hypotension in paraplegic surgery as 57 per cent, but have not given the number of patients. The anaesthetic records of this hospital revealed that 218 patients had operations on the spine during the last eight years. It was found that of the 88 patients who were paraplegic or paretic, 37 had a fall in blood pressure of $40 \mathrm{~mm} \mathrm{Hg}$ or more at some stage of the anaesthetic procedure, i.e. 42.04 per cent. This can be compared with the non-paraplegic cases, where out of 130 patients only eight showed hypotension of the same degree, the percentage being 6.1 in these cases. We were unable to find reference to cardiac arrest in cases of this type.

\section{SUMMaRY}

The cases of two paraplegic patients who had cardiac arrest at the time of shifting to the prone position after induction of anaesthesia are described and discussed. Both patients could be revived. One of them was reanaesthetized and successfully operated upon 16 days later, with precautions against hypotension.

\section{RÉSUMÉ}

On décrit et on analyse les cas de deux paraplégiques qui ont eu un arrêt cardiaque au moment où on les tournait en position ventrale après l'induction de l'anesthésie. Les deux cas ont été réanimés. L’un des deux a pu subir une nouvelle anesthésie et être opéré avec succès seize jours plus tard, en ayant soin de ne pas laisser la pression s'abaisser.

\section{REFERENCES}

1. Pollock, L. J.; Boshes, B.; Chor, H.; Finkelman, I.; Arieff, A. J.; \& Brown, M. Defects in Regulatory Mechanisms of Autonomic Function in Injuries to Spinal Cord. J. Neurophysiol. 14: 87 (1951).

2. WilliaMs, W. T.; Walker, J. W.; \& Jackson. Shock: A Surgical Hazard in the Paraplegic. Surgery. 42: 664 (1957).

3. Hunter, A. R. Neurosurgical Anaesthesia. Oxford: Blackwell Scientific Publications (1964), p. 191.

4. Guttmann, L. \& Whittridge, D. Effects of Bladder Distension on Autonomic Mechanisms after Spinal Cord Injuries. Brain. 70:36 (1947). 